\title{
Effect of Accident Prevention Program on Nursery School Teachers knowledge and Practices.
}

\author{
Shaima Shaban Mohamad (1), Dr. Afkar Ragab Mohamad (2).Dr .Sanaa Mahmoud Ahmed (3)
}

Assisstant lecturer of Pediatric Nursing, Faculty of Nursing Minia University.

Professor of Pediatric Nursing, Faculty of Nursing, Cairo University.

Assisstant professor of pediatric Nursing, Faculty of Nursing, Minia University.

\section{Abstract}

Background: Accidents are a major cause of morbidity and mortality in children. Along with cardiovascular diseases and cancers, accidents currently form the 3rd leading causes of morbidity and mortality in developed and developing countries. Aim: The study aimed to evaluate the effect of accident prevention program on nursery school teachers' knowledge and practices. Research design:A pre/post quasi-experimental research design was used in this study. Sample: A convenient sample of 60 nursery school teachers, 30 from private and 30 from governmental nursery schools. Setting: The selected nursery schools represented all geographic areas of Minia city. Tools: pre-designed questionnaire sheet was used to collect data from teachers which include part 1: Demographic data about teachers as age, marital status, qualifications, years of experience and previous training courses. Part 2 Teachers' knowledge about accident prevention and first aid. An observational checklist was used for first aid measures. Results: The study results revealed that the majority of the studied teachers were married and more than two fifth of them had $>30$ years old with a mean of age $33.32 \pm 7.478$.years. The total mean scores of both knowledge and practice were increased after implementation of the program with statistical significant differences at ( $p$-value 0.0001 ) between pretest, immediate posttest and posttest after 3 months. Conclusion: The current study concluded that there was an increase in the mean scores of teachers' knowledge and practices after implementation of the program about accident prevention and first aid. Recommendation: The study recommended a wide coverage implementation of this research about accident prevention and first aid for the nursery school teachers all over Minia City nursery schools.

Keywords: Accident prevention, Nursery school, Teachers, First aid.

\section{Introduction}

Accidental injuries in young children are often serious, but are largely preventable with appropriate information and safe practices. Young children are particularly vulnerable to accidents due to their innate desire to explore their world and the inability to perceive the dangers of their actions. As children learn through experience, minor injuries are inevitable but providing a safe environment can reduce the risks (Akturk\& Erci ,2016).

Every day nearly2, 300 children and adolescents die from injuries sustained from motor vehicle injuries, drowning, poisoning, falls, burns, and violence. Overall, more than $95 \%$ of all injury-related deaths occur in low- and middle-income countries (LMICs) in all age groups. In highincome countries (HICs), injuries account for more than $40 \%$ of all deaths among children and adolescents Many of those who do not die due to these injuries are at an increased risk of lifelong disabling health consequences (World Health Organization, 2015).

The climbing and running activity of the typical toddler is complicated by total neglect and lack of appreciation of danger, immature coordination, and a high center of gravity. Falling from furniture is a major cause of injury, with more children in this age-group sustaining head injuries than older children (Hockenberry \& Wilson, 2017 ).

Developmental and behavioral properties including unawareness of hazards and being active as well as physical properties including narrower airways, smaller body mass predispose children to injuries and carry a higher risk. Usually; children have minor bruises but at times, they may face major injuries resulting in fractures, bleeding, fainting thus, first aid like medical management is important (Masih et al;2014 ) Children spend a significant portion of their day in kindergarten. Therefore, pediatric emergencies due to unintentional accident that may results in physical injuries are more likely to occur in this setting. In the absence of parents or caregivers, kindergarten is the best place to give care to children (Muneeswari , 2014).

First aid is an urgent attention delivered to victims of sudden illness or injury until medical helps arrive. So that, early treatment of such emergencies decreases morbidity and deaths (Khatatbeh, 2016) First aid can be obtained by everybody and comprises self-care, so that first aider can be any person exist in the scene of emergency and provides such care like parents, teachers, policeman, fireman, first responder, professional medic, etc (Singletary, et al., 2015).

Pediatric nurses can play an important educational role by teaching caregivers about expected behaviors for their child's upcoming developmental stage. This alerts them to the types of injuries common to that age group and to potential environmental hazards (Potts, \& Mandleco, 2012). Nurses can initiate safety programs in schools, neighborhoods and cities. Nurses have important roles particularly in education. Unfortunately, not all schools in have health professionals. Thus, even small accidents could cause difficult situations because of teachers who do not know how to intervene or who intervene wrongly. For instance, as s/he does not know how to do first aid, the teacher gets nervous and thus cannot help the student. Therefore, nurses, particularly those who have the health educator role, should visit schools in some certain intervals 
and give basic first aid education. This way, teachers could perform first aid in a more conscious and rapid manner (Arli \& Yildirim, 2017).

Teachers are almost the first and the main caregiver represented the first line to protect school children, in addition, teachers' role complements the parent's role. School teachers during the school hours, are the real firstrespondent to emergencies, injuries resulting from school accidents. Therefore, they have to be capable to act accurately with health emergencies affected the school children (Sönmez et al., 2014).

\section{Significance of the study}

Children spend a significant portion of their day in the kindergartens, so pediatric emergencies such as the accidental physical injuries are more likely to occur in those settings. Kindergartens are the best place to give care to those children in absence of mothers (Muneeswari, 2014). Kindergarten teacher has crucial role in caring for children, supervision and prevention of health hazards. They should be well trained on first aid and emergency control to save children lives and the first aider should have adequate knowledge and skills about what is he doing and be encouraging and reassuring to the victims (Olympia, et al., 2010) . In Egypt, 2009, more than 746,000 injured cases were registered in to the Ministry of Health hospitals. Around $38 \%$ of all injuries occur among children and young adults less than 20 years of age (El -Sayed, 2012).

While in Egypt 2013 the mortality rate from injury in children less than five years was 3\% of total death. (WHO, 2013) and the mortality rate of children under five years from injury at 2014 was $4 \%$ of total death in Egypt (WHO, 2014). And in Egypt too the mortality rates from unintentional poisoning were 0.5 per 100000 population in 2015 (WHO, 2015).

In the nursery schools at Minia city, children are more susceptible to accidents and injuries because of their large numbers in relation to teachers' numbers which predispose them to accident because lack of supervision.

\section{The aims of the current study were to:}

- Assess the knowledge and practices of nursery school teachers about accident prevention and first aid measures

- Develop and apply the program for nursery school teachers' about accident prevention and first aid measures for common childhood accident.

- Evaluate the effect of accident prevention and first aid program on nursery school teachers' knowledge and practices

\section{Research Hypothesis}

- There will be a significant difference between the nursery school teachers' knowledge and practices about accident prevention and first aid after receiving an educational program.
- There will be a significant association between teachers' knowledge and reported practice and demographic characteristics of the studied teachers.

\section{Subject and Methods \\ Research design:}

Pre / post quasi-experimental research design was used in this study. A quasi experimental design is one type of experimental design that is very similar to the true experimental design except there is loss one criteria which is control, manipulation, or randomization (Burns \& Grove, 2012).

\section{Setting:}

The selected nursery schools represented all geographic areas of Minia city including both private nursery schools (El Zahra El - Ganobia and Salah El Dien) and governmental nursery schools (El-Fath nursery school and LogatKafr El-Mansoura) Kafr El -Mansoura nursery school was changed to (El -Tagrebia nursery school ) because of refusal of the director to conduct the program there.

\section{Sample:}

A convenient sample of 60 nursery school teachers, 30 from private and 30 from governmental nursery schools.

Sample size was calculated by $\mathrm{G}$ power program depending on mean Score of total knowledge pre (17.40 \pm $15.35)$ and post $(39.40 \pm 11.61)$ as resulted by (Mersal \& Aly, 2016) at power of $97 \%$. The calculated sample was 52 increased to 60 to avoid dropouts.

\section{Tools for data collection:}

Pre-designed questionnaire sheet for nursery school teachers as pre/ posttest that was designed by the researcher in an Arabic language after reviewing of the related literature to assess the nursery school teachers' knowledge toward accident prevention and first aid. It comprised the following parts;

Part I: Demographic data about teachers as teacher's age, marital status, qualifications, years of experience and previous training courses.

Part 2 : This part was including the following;

Teachers' knowledge about accident prevention and first aid which include: Definition, types and risk factors for accident include (5questions)Definition ,causes and types of wound, fracture, burn and suffocation include (16 questions) meaning of first aid and first aid measures for common childhood accident at nursery school (12questions).

An observational checklist was used to assess first aid measures about wound, epistaxis, convulsion, suffocation, poisoning, fractures, burn and fainting.

\section{Scoring system:}

Scores of teachers' knowledge was one score for correct answer and zero for incorrect answer. These scores 
were converted into a percent. The teachers' knowledge was considered satisfactory if the percent is $60 \%$ or more and unsatisfactory if less than $60 \%$. While Scoring of teachers' practices was one score for done skill, and zero score was given for not done skill,. These scores were converted into a percent. The teachers' practices were considered satisfactory if the percent score was $60 \%$ or more and unsatisfactory if less than $60 \%$. The observations were carried out in pre- test and post- test to assess the teachers' practice about first aid measures.

Educational and training program was designed in Arabic form of educational program by the researcher based upon the actual need assessment of teachers. It was also supplemented with information based on review of relevant literature (nursing textbook, journals and internet resources) about accident prevention and first aid.

\section{The program}

The program was designed by the researcher. A review of the past and current available literature in various aspects of the problems using textbooks, articles, periodicals and magazines was necessary to be acquainted with all aspects of the study problem and also in order to develop relevant tools for data collection.

The time and methods of training sessions was organized according to the time available for the teachers in each nursery school, the time required for the program implementation was six months, the total duration of the program was18hours, 1hour orientation, 2hours pretest and 15 hours for the program sessions. Implementation of the program was done for each group with 5 hours theoretical and 10 hours practical, the program sessions was 12 sessions for each group, each session lasted (60- 120 minutes ), two sessions per day, the nursery school teachers divided into 8 groups each group had 7:8 teacher, the teachers are interviewed two days per week from $9 \mathrm{am}: 12 \mathrm{pm}$ to cover all information about accident prevention and first aid .Different teaching methods were used to motivate and reinforce teaching such as praising and recognition during the program sessions. The method of teaching which used during the program sessions were lectures, discussion, pictures, poster ,brochure and videos for easily understanding and demonstration.

The procedures of first aid were performed on the doll and the real equipment and supplies for first aid was used to facilitate education and training of the teachers.

The program was revised by medical and pediatric nursing specialist. A copy of program in a form of Arabic booklet was given for each participant. The "post-test" carried out immediately and after three months following implementation of the training program to evaluate the effect of the program on nursery school teachers' knowledge and practices about accident prevention and first aid.

The methods of teaching which used during the program sessions were lectures, discussion, pictures, poster ,brochure and videos for easily understanding and demonstration The procedures of first aid was performed on the doll and the real equipment and supplies to facilitate education and training of the teachers.

\section{Validity and reliability}

Data collection tools were tested for content and face validity by three of experts in the field of pediatric nursing to test tool validity.

Cronbach alpha coefficient test was used to assess the reliability of the tool to confirm its consistency. It was 0.70 and .71 respectively.

\section{Pilot study}

After developing the tools, a pilot study was conducted on $10 \%$ (6) of the teachers at Minia city nursery schools. A pilot study was conducted to test clarity, and visibility as well as to determine the time required for filling the data sheets. According to the results of pilot, the needed modification, omissions and/or additions for some items were done.

\section{Ethical consideration}

Primary approval was obtained from ethical committee, Faculty of Nursing, Minia University. An oral consent was taken from all teachers to participate in the study. The purpose and nature of the study were explained by the researcher through direct personal communication prior starting to the conduction of the study. This data will be confidential and it will be used for the purpose of the research only.

\section{Data Collection Procedure}

Primary approval was obtained from ethics committee, Faculty of Nursing, Minia University .An official permission was obtained from the directors of the nursery schools. A total of 60 nursery school teachers were divided in to two groups, 30 from private and 30 from governmental nursery schools. The researcher gathered data of the study through personal interviewing of the studied teachers, pretest was done to assess the nursery school teachers' knowledge and practices about accident prevention and first aid. The time and methods of training sessions was organized according to the time available for the teachers in each nursery school. The teachers were interviewed two days / week from 9 am to $12 \mathrm{pm}$. The program was conducted over two sessions / day to cover all information about accident prevention and first aid. The method of teaching used during the program sessions were lecture, discussion, and use of illustrated pictures for easily understanding and demonstration.

\section{Statistical analysis}

Data entry was done using compatible personal computer. Statistical analysis was done using SPSS-20 statistical software package and excel for figures. The content of each tool was analyzed, categorized and then coded. Data were presented using descriptive statistics in the form of frequencies and percentages for qualitative variables, means and standard deviations for quantitative variables. Quantitative continuous data were compared by using student T-test in case of comparisons between the mean scores of the two studied groups. Qualitative studied variables were compared using Chi-square test. Statistical significance used at $\mathrm{P}$ value $<0.05$. 


\section{Results:}

Table (1): Distribution of the Studied Teachers According to Their Demographic Characteristics (No. $=60)$

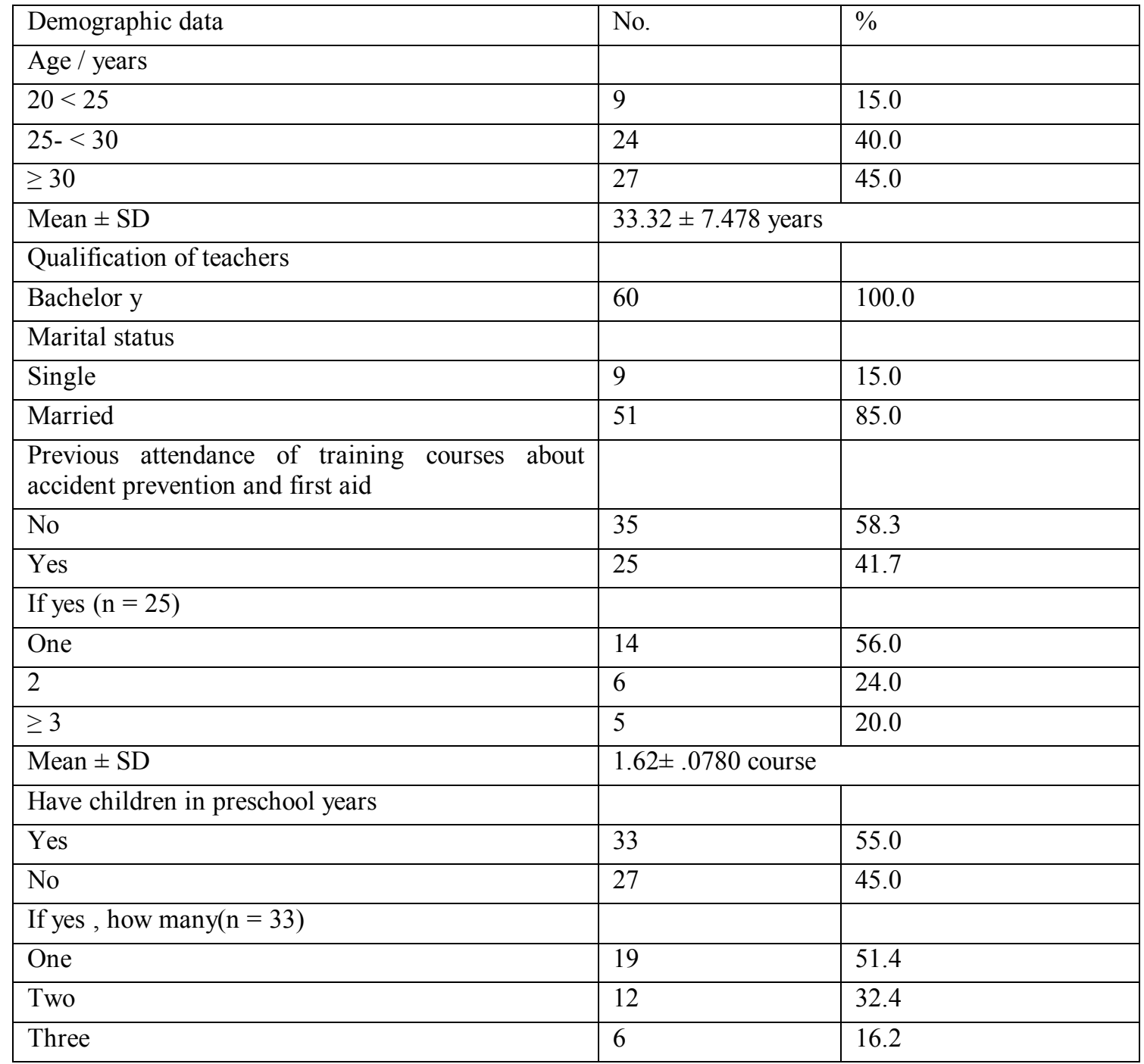

Table (1) Illustrates that more than two fifth of the studied teachers $(45 \%)$ had $>30$ years old with a mean of age $33.32 \pm 7.478$. All the teachers $(100 \%)$ had Bachelor of Science, while more than two fifth of them $(41.7 \%)$ attended training courses, more than half of those who attended training courses $(56 \%)$ attended one course. The majority of the studied teachers $(85 \%)$ were married; more than half of them $(51.4 \%)$ had one child.

\section{Table (2): Frequency Distribution of Teachers ' knowledge about Past History of Accident}

\begin{tabular}{|l|l|l|}
\hline \multirow{2}{*}{ Knowledge about past history of accident } & \multicolumn{2}{l|}{$\begin{array}{l}\text { Past history of accident } \\
\text { No }=60\end{array}$} \\
\cline { 2 - 3 } & No & 66.7 \\
\hline Yes & 40 & \\
\hline Type & & 57.5 \\
Closed wound & 23 & 17.5 \\
Open wound & 7 & 10 \\
Epistaxis & 4 & 15 \\
Fracture & 6 & \\
\hline
\end{tabular}

Table (2) proved that more than half $(57.5 \%)$ of the teachers has confronted with closed wounds to the children compared to $10 \%$ of them has exposed to epistaxis during their years of working in nursery school. 
Table (3): Comparison of Teachers' Knowledge Pretest ， Immediate Posttest and After 3 Months Posttest Regarding Accidents

\begin{tabular}{|l|l|l|l|l|l|}
\hline \multirow{2}{*}{$\begin{array}{l}\text { Teachers } \\
\text { knowledge }\end{array}$} & \multicolumn{2}{|l|}{ Times } & Friedman & P \\
\cline { 2 - 5 } & Pretest & & \multicolumn{2}{|l|}{ Test } & \\
\hline Accident & $4.33 \pm .914$ & $4.82 \pm .431$ & $4.70 \pm .530$ & 14.127 & $0.001^{* *}$ \\
\hline Wound & $1.83 \pm .740$ & $2.70 \pm .591$ & $2.63 \pm .520$ & 46.936 & $0.0001^{* *}$ \\
\hline Fracture & $1.83 \pm .740$ & $2.70 \pm .591$ & $2.63 \pm .520$ & 46.936 & $0.0001^{* *}$ \\
\hline Burn & $1.80 \pm .777$ & $2.78 \pm .490$ & $2.57 \pm .593$ & 45.612 & $0.0001^{* *}$ \\
\hline Suffocation & $1.48 \pm .567$ & $1.92 \pm .279$ & $1.73 \pm .446$ & 21.552 & $0.0001^{* *}$ \\
\hline Convulsion & $1.18 \pm .596$ & $1.87 \pm 0.389$ & $1.90 \pm .399$ & 60.088 & $0.0001^{* *}$ \\
\hline Fainting & $1.60 \pm .616$ & $1.92 \pm .279$ & $1.93 \pm .252$ & 19.831 & $0.0001^{* *}$ \\
\hline Poisoning & $0.72 \pm .454$ & $1.00 \pm .000$ & $0.98 \pm .129$ & 30.333 & $0.0001^{* *}$ \\
\hline First Aid & $7.63 \pm 2.163$ & $11.85 \pm 1.436$ & $12.28 \pm .904$ & 89.653 & $0.0001^{* *}$ \\
\hline $\begin{array}{l}\text { Total } \\
\text { Scores }\end{array}$ & $22.08 \pm 3.702$ & $30.98 \pm 3.165$ & $30.72 \pm 3.858$ & 78.538 & $0.0001^{* *}$ \\
\hline
\end{tabular}

Table (3) Illustrated that in immediate posttest the teachers had the highest mean score related to their knowledge about accident, wound, fracture, burn, suffocation, convulsion, fainting, poisoning, first aid knowledge and the total knowledge of the teachers about accident prevention and first aid with highly statistical significant difference between pretest, immediate posttest and posttest after 3 months at p-value 0.0001, except accident; the significant differences was p-valueat 0.001

Table (4): Comparison of Teachers' Practices Pretest /Immediate and after 3 Months Posttest

\begin{tabular}{|l|l|l|l|l|l|}
\hline Teachers ' Practice & Pretest & $\begin{array}{l}\text { Immediate post } \\
\text { test }\end{array}$ & $\begin{array}{l}\text { Post test } \\
\text { after 3 months }\end{array}$ & F \\
\hline First aid for wound & $1.33 \pm 0.774$ & $6.43 \pm 0.909$ & $5.82 \pm 0.965$ & 98.879 & $0.001^{*}$ \\
\hline First aid for fracture & $1.45 \pm .964$ & $5.62 \pm .846$ & $5.22 \pm .804$ & 97.700 & $0.001^{*}$ \\
\hline First aid for burn & $0.88 \pm .885$ & $5.62 \pm 846$ & $4.02 \pm .770$ & 101.971 & $0.001^{*}$ \\
\hline First aid for epistaxis & $1.48 \pm 1.112$ & $5.38 \pm 0.922$ & $4.80 \pm 0.840$ & 94.731 & $0.001^{*}$ \\
\hline $\begin{array}{l}\text { First aid for } \\
\text { convulsion }\end{array}$ & $0.57 \pm 0.722$ & $5.18 \pm .930$ & $4.57 \pm 0.909$ & 102.945 & $0.001^{*}$ \\
\hline First aid for fainting & $1.20 \pm .898$ & $5.59 \pm .938$ & $5.45 \pm 1.016$ & 101.591 & $0.001^{*}$ \\
\hline First aid for poisoning & $1.15 \pm 0.860$ & $5.73 \pm 0.880$ & $5.43 \pm 1.064$ & 97.714 & $0.001^{*}$ \\
\hline $\begin{array}{l}\text { First aid for } \\
\text { suffocation }\end{array}$ & $1.92 \pm 1.046$ & $5.97 \pm 1.057$ & $5.85 \pm 1.143$ & 93.945 & $0.001^{*}$ \\
\hline $\begin{array}{l}\text { Total first aid } \\
\text { practices. }\end{array}$ & $9.98 \pm 2.891$ & $44.20 \pm 4.701$ & $41.20 \pm 4.881$ & 97.414 & $0.001^{*}$ \\
\hline
\end{tabular}

Table (4) Illustrated that in immediate posttest the teachers had the highest mean scores related to their practices about wound, fracture, burn, epistaxis, convulsion, fainting, poisoning, suffocation and total score of first aid with highly statistical significant difference in pretest, immediate, posttest and posttest after 3 months at pvalue 0.0001 .

Table (5) Correlation between The Total Scores of Teachers' Knowledge and Demographic Characteristics of the Studied Teachers .

\begin{tabular}{|c|c|c|c|c|c|c|}
\hline \multirow[t]{3}{*}{ Demographic Characteristics } & \multicolumn{6}{|c|}{ Total knowledge Scores } \\
\hline & \multicolumn{2}{|c|}{ Pretest } & \multicolumn{2}{|c|}{ Immediate } & \multicolumn{2}{|c|}{ Posttest after 3 months } \\
\hline & $\mathrm{R}$ & $\mathrm{P}$ - value & $\mathrm{R}$ & $\mathrm{P}$ - value & $\mathrm{R}$ & $\mathrm{P}$ - value \\
\hline Age & 0.036 & 0.786 & 0.016 & 0.904 & .030 & 0.819 \\
\hline Marital status & 0.010 & 0.942 & 0.121 & 0.356 & 0.117 & 0.375 \\
\hline
\end{tabular}




\begin{tabular}{|c|c|c|c|c|c|c|}
\hline \multirow[t]{3}{*}{ Demographic Characteristics } & \multicolumn{6}{|c|}{ Total knowledge Scores } \\
\hline & \multicolumn{2}{|c|}{ Pretest } & \multicolumn{2}{|c|}{ Immediate } & \multicolumn{2}{|c|}{ Posttest after 3 months } \\
\hline & $\mathrm{R}$ & $\mathrm{P}-$ value & $\mathrm{R}$ & $\mathrm{P}-$ value & $\mathrm{R}$ & $P$-value \\
\hline $\begin{array}{l}\text { Have children in preschool } \\
\text { years }\end{array}$ & 0.240 & 0.065 & 0.144 & 0.274 & 0.108 & 0.411 \\
\hline If yes how many children & 0.138 & 0.835 & 0.035 & 0.815 & 0.040 & 0.415 \\
\hline Years of experience & 0.03 & 0.981 & 0.033 & 0.800 & 0.540 & 0.682 \\
\hline Attended training courses & 0.167 & 0.203 & 0.037 & 0.780 & 0.160 & 0.223 \\
\hline
\end{tabular}

Table (5) clarified that there were no statistical significant correlation between the teachers' knowledge and all items of their demographic characteristics.

Table (6): Correlation between the Total Scores of Teachers' Practices and Their Demographic Characteristics.

\begin{tabular}{|c|c|c|c|c|c|c|}
\hline \multirow{3}{*}{$\begin{array}{l}\text { Demographic } \\
\text { Characteristics }\end{array}$} & \multicolumn{6}{|c|}{ Total practice scores } \\
\hline & \multicolumn{2}{|l|}{ Pretest } & \multicolumn{2}{|c|}{ Immediate } & \multicolumn{2}{|c|}{ Posttest after 3 months } \\
\hline & $\mathrm{R}$ & $\mathrm{P}$ - value & $\mathrm{R}$ & $\mathrm{P}-$ value & $\mathrm{R}$ & $\mathrm{P}-$ value \\
\hline Age & 0.005 & 0.968 & 0.060 & 0.647 & 0.053 & 0.687 \\
\hline Marital status & 0.063 & .0634 & 0.212 & 0.103 & 0.060 & 0.650 \\
\hline $\begin{array}{l}\text { Have children in } \\
\text { preschool years }\end{array}$ & 0.147 & 0.263 & 0.206 & 0.115 & 0.030 & 0.817 \\
\hline If yes how many & $0.418^{*}$ & $0.010^{*}$ & 0.003 & 0.984 & .069 & 0.684 \\
\hline Years of experience & 0.000 & 0.999 & 0.021 & 0.874 & 0.021 & 0.874 \\
\hline $\begin{array}{l}\text { Attended training } \\
\text { courses }\end{array}$ & $-.066-$ & .617 & 0.015 & 0.912 & 0.077 & 0.560 \\
\hline
\end{tabular}

Table (6) proved that there were no statistical significant correlation between the teachers' practices and all items of their demographic characteristics except for number

\section{Discussion}

Accidents are a major cause of morbidity and mortality in children. Along with cardiovascular diseases and cancers, accidents currently form the 3rd leading causes of morbidity and mortality in developed and developing countries (Suguna, 2015). Toddlers and preschoolers are at risk for many types of accidents and unintentional injuries such as those caused by unsafe toys, fall, burns or scalds, drowning, motor vehicle crashes and poisoning (Allender et al., 2013).

As regard personal characteristics, It was observed that more than two fifth of the studied teachers aged $\geq 30$ years with a mean of $33.32 \pm 7.478$ years. This result contradicted with Mersal and Ali (2016) Who found in their study about developing disaster management and first aid guidelines for school teachers in Cairo Egypt that more than two fifth of the school teachers aged 40 years and more. Concerning marital status; the majority of the studied teachers were married, This result is consistent with Younis and El-Abassy 2015) who conducted a study about Primary school teachers' first aid management of children' school day accidents: Video-assisted teaching method versus lecture method and found that the majority of the studied teachers were married. Regarding having preschool age children; more than half of the studied teachers had one child. This is contraindicated withMasih (2014) who

P a g e | 125 of children where there was positive statistical correlation with $\mathrm{p}<0.01$.

conduct a study on primary school teachers' knowledge and practice regarding first aid management for children and stated that nearly three quarters had more than one child. The number of children might contribute to the experience with first aid and care of childhood accidents. Regarding years of experience nearly half of the teachers had work experience $>10$ years with a mean $10.23 \pm 6.919$ years. This attributed to reduction in the employment rate by Ministry of Education in Egypt in the last years which lead to reduction of numbers of recently employed teachers.

The study result was consistent with Bhesaniaet al., (2014) who found in their study about Knowledge, attitude and practices of school teachers towards epileptic school children in Karachi, Pakistan that Overall half of teachers had teaching experience of more than 10 years. This result was disagreed with Thomas and Therese,(2016) in their study about "assessment of the effectiveness of selfinstructional module on knowledge regarding selected first aid measures among primary school teachers in Ernakulam district; they found that nearly half were having 0-5 years of experience.

Regarding previous attendance of training courses about accident prevention and first aid; more than half of the studied teachers didn't attended training courses, this result was matched with Mersal and Ali (2015) who found that more than two thirds of the teachers were not 
trained on first aid. Similarly the current study results were in the same line with Younis and El-Abassy (2015) in their study about Primary teachers' first aid management of children's school day accidents: Video-assisted teaching method versus lecture method and indicated that the highest percentage of the school teachers did not attend any training courses.

The teachers' knowledge about accident prevention and first aid was insufficient in pretest before implementation of the program, so the teachers were in a massive need for the program about accident prevention and first aid.

Lack of knowledge and practices of the teachers about accident prevention and first aid before intervention may be attributed to the lack of effective practical emergency care training in the curriculum of the faculty of specific education, absence of training programs about accident prevention and first aid conducted in the nursery schools for the teachers as well as lack of educational pictures, posters or movies that illustrate how to give first aid and lack of supplies and equipment in the selected nursery schools.

The results of the study achieved the study hypothesis which stated that there was a significant difference between the nursery school teachers' knowledge and practices about accident prevention and first aid after receiving the program since the teachers' knowledge and practices were improved after the program.

Regarding knowledge about fracture the study results revealed that there was statistical significant difference in immediate posttest as clarified by the mean score in immediate posttest $2.70 \pm .591$ compared with $1.83 \pm .740$ in pretest with highly statistical significant difference at $\mathrm{p}$. value 0.0001 , the study results were matched with the results of the study done by Thomas and Therese (2015) they found that the mean score of teachers knowledge about fracture was $6.83 \pm 0.86$ in immediate posttest compare with $4.65 \pm 1.54$ in pretest

Concerning poisoning there was an observed improvement in the total score of knowledge in immediate posttest with a mean score $1.00 \pm .000$ compared to 0.72 \pm 0.454 in pretest with a highly statistical significant difference $(p=0.0001)$. These results were in agreement with Alexandropoulou (2013) in a study on evaluating a health educational first aid program for special education school personnel: a cluster randomized trial and found that the total knowledge mean score was $1.82 \pm 1.87$ in pretest compared with $4.48 \pm 2.2$ in immediate posttest regarding poisoning.

The results of the current study showed an increase in the teachers' knowledge about fainting in immediate posttest $1.92 \pm .279$ compared to pretest which was $1.60 \pm .616$ with highly statistical significant difference at $p$-value 0.0001 . This results was in congruence with Mohammed and El Sayed (2013) who stated that participants' knowledge regarding sunstroke and fainting was improved immediately after the program implementation, there was a statistical significant difference in participants' knowledge regarding sunstroke and fainting between before and immediately after the program implementation $(p=0.000)$ and Mean score of the participants' knowledge regarding sunstroke and fainting was $(1.222 \pm 0.808)$ prior the program, which improved to P a g e | 126
$(2.555 \pm 0.704 \& 2.777 \pm 0.427)$ immediately after the program and 6 months later.

The current study demonstrated an increase in the total knowledge mean scores about accident prevention and first aid with a mean $22.08 \pm 3.702$ before the program while in the immediate posttest and posttest after 3months the mean was $30.98 \pm 3.165$ and $30.72 \pm 3.858$; respectively with highly statistical significant difference at $\mathrm{p}$ - value 0.0001. on the same context Mersal and Ali, (2016) found that the total means score of first aid knowledge pre and post intervention were $(17.40 \pm 15.35)$ and $(39.40 \pm 11.61)$ respectively with statistical significance difference at $(\mathrm{p}$ value $>.000)$.

The results of the current study were also consistent with Abdella, et al (2015) on their intervention program for the kindergarten teachers about pediatrics first aids, the study results revealed that highly statistical significant difference was found in the studied group in the posttest and follow up intervention in comparison to pre intervention. Additionally; the mean and SD of total knowledge for pre- test, immediate and follow intervention were $22.2 \pm 5.0,35.7 \pm 4.7$ and $33.3 \pm 5.3$; respectively.

Our study revealed that there was improvement in performance of the studied teachers toward common first aid of emergency situations such as wound, fracture, burn, epistaxis, convulsion, fainting and total first aid practice with a mean and SD 4.82 $\pm .431,2.70 \pm .591,2.70 \pm .591$, $2.78 \pm .490, \quad 1.92 \pm .279, \quad 1.87 \pm 0.389$ and $44.20 \pm 4.701$; respectively in immediate posttest compared to pretest with highly statistical significant difference at (p. value 0.0001 )

The results of the current study matched with the results of Hegazye et al (2014) in their study about impact of a disaster educational program on knowledge and practices of teachers among primary governmental schools, Cairo governorate that the mean score of teachers' practices showed significant increase in immediate posttest $9.74 \pm 0.66, \quad 5.58 \pm 0.57, \quad 9.20 \pm 1.03, \quad 3.66 \pm 0.51$, $3.7 \pm 0.64$ and $50.52 \pm 2.27$ respectively; regarding wounds ,bleeding, fainting , burn, fracture and mean score of total practices with highly statistically significance differences between all practice subscales scores regarding applying first aid procedures at $\mathrm{p}$ - value 0.0001 .

The current study revealed that more than two thirds of the studied teachers reported that they confronted with accidents during their years of experience, between these accidents more than half of the teachers confronted with closed wounds followed by open wounds, fractures and nose bleeding. The study results was similar to the results of the study done by Masih et al (2014) about Knowledge and practices of primary school teachers about first aid management of selected minor injuries among children and indicated that more than two thirds of them experienced previous injuries in school children. Similarly, in the study conducted by Kumar et al (2013) it was observed that wound was found to be the most common event in the school campus requiring first aid. High percentage of wounds and bleeding denoted among pupils as a type of incidence.

During studying correlation between the teachers' knowledge and their demographic characteristics the present study results revealed that there was no statistical significant correlation between the teachers' pre and post program

Shaima S., et al 
knowledge and their demographic characteristics such as age, years of experience, marital status and previous attendance of training courses.

Concerning the teachers' age the study results is agreedwith Deepak, (2012) who concluded that there was no statistical significant correlation between participants' age and first aid knowledge ( $>0.05)$. While Morsey et al (2017) showed that a positive correlation was found between age, knowledge, and practices regarding first aid and crisis management

Moreover the study results disagreed with Mersal and Ali, (2016) in their study about developing disaster management and first aid guidelines for school teachers in Cairo Egypt and found that there was positive correlation ( $p$ $>$.000) between age, previous training and experience, and between their knowledge and practice of first aid.

In studying correlation between the teachers' practices and their demographic characteristics the present study results revealed that there was no statistical significant correlation between the teachers pre and post practices and their demographic characteristics; except for number of children the results revealed that there was positive correlation for teachers who had the large number of children in pretest at $\mathrm{p}$ - value $<0.01$. So having more than two children can make deference especially with female teachers.

The result of the current study was agreed with El Wardany et al (2017) in their study about "Impact of training program regarding first aid knowledge and practices among preparatory schools' teachers at Assiut City" and clarified that there weren't any statistical significance differences between teachers' age, level of education, sex and years of experience with the total score of practices in pre/posttest. These results are contradicted with Riad et al (2013) who revealed a positive correlation between age, knowledge, experience and practices regarding first aid and crisis management.

\section{Conclusion:}

In the light of the results the study it was concluded that the majority of the studied teachers were married; more than half of them didn't attend training courses. Two thirds of the studied teachers had confronted with childhood accidents during their years of working, and the teachers' knowledge and practices about accident prevention and first aid showed an observed increase with highly statistical significant differences in most items in immediate posttest and in posttest after 3 months compared to pretest with p-value 0.0001. In addition there was no statistical significant correlation between the teachers knowledge and practices and their demographic characteristics except for number of children.

\section{Recommendations}

- Health promotion programs about accident prevention and first aid should be directed toward teachers in nursery schools in all private and governmental levels.
- The course content of the undergraduate students in the Faculty of kindergarten should include training beside the theoretical lectures on first aid.

- The school authority should provide the teachers with booklet, posters, brochures, charts, equipment's and supplies to improve their knowledge and practices about accident prevention and first aid.

- Wide coverage of investigating and implementing of these research findings all over Minia City nursery schools is needed.

\section{References}

[1]. Abdella , N. A ., Abu-Elenen , N. M., El-kazaz, R. H., \& Moussa, M. (2015). Intervention program for th kindergarten teachers about pediatrics first aids. American Journal of Research Communication, 3(5), 178-194.

[2]. Akturk, Ü., \& Erci, B. (2016). Determination of Knowledge, Attitudes and Behaviors Regarding Factors Causing Home Accidents and Prevention in Mothers with a Child Aged 0-5 Years. Journal of Education and Practice, 7(18), 142-153.

[3]. Alexandropoulou , M., (2013).Evaluating Health Educational First Aid Program for Special Education School Personnel: a Cluster Randomized Trial. International Journal of Caring Sciences, 6(1), 115-126.

[4]. Allender , J., Rector, C., \& Warner, K. (2013) .Community \& public health nursing: Promoting the public's health. Lippincott Williams \& Wilkins. chapter 21, Maternal child health: working with perinatal, infant, and preschool clients; p. 673.

[5]. Arli S.K., Yildirim, Z. (2017).The Effects of Basic First Aid Education on Teachers' Knowledge Level: A Pilot Study Volume 10 | Issue 2| 813 International Journal of Caring Sciences

[6]. Bhesania, N.H., Rehman, A., Savul ,I. S., \&Zehra, N. (2014). Knowledge, attitude and practices of school teachers towards epileptic school children in Karachi, Pakistan. Journal of medical sciences, 30(1), 220-224.

[7]. Burns, N., \& Grove, S.K.(2009). The practice of nursing research $\square$ : appraisal, synthesis, and generation of evidence. St. Louis, Mo: Saunders Elsevier.

[8]. Deepak, M.(2012). A study on assessment of knowledge on practice regarding first aid measures among the self-help groups in selected areas of Mangalore with a view to develop information module. Age (yrs), 1, 25-30.

[9]. El-sayed H. Zekry O, Abdel Hamid S, et al. Pattern and severity of childhood unintentional injuries in Ismailia city, Egypt. Africa Safety 
Promotion Journal.2012;b10 (2). World Bank , 2014.

[10]. Elwardany , A. S.,\& Khalaf, S. A. R. (2017) .Impact of training program regarding first aid knowledge and practices among preparatory school teachers at Assiut City. Journal of Nursing Education and Practice, 7(12), 89.

[11]. Hockenberry ,M. J., \& Wilson, D. (2014). Wong's nursing care of infants and children .10 th ed. , Canada : Elsevier. Chapter13: Health promotion of toddlers and preschoolers: p399.

[12]. Kumar, S. D., Kulkarni, P., Srinivas, N., Prakash, B., Hugara, S.,\& Ashok, N. C. (2013).Perception and practices regarding first-aid among school teachers in Mysore. Natl. J.Community Med., 4(2), 349-352.

[13]. Masih S, Sharma R, Kumar A (.2014) Knowledge and practice of primary school teachers about first aid management of selected minor injuries among children. International Journal of Medicine and Public Health,4(4),45862.

[14]. Mersal , F. A., \& Aly, R. A. E. S. (2016). Developing disaster management and first aid guidelines for school teachers in Cairo Egypt. Journal of Nursing Education and Practice, 6(7), 41.

[15]. Mahmoud, M. H., \& El -sayd, S. M. (2013).).Designing and implementing a first aid program for employees of female health Colleges at Najran University, International Journal of Advanced Research, 1 (9) 269- 285.

[16]. Morsy, W.Y., Badawy, A.., Elayat W.(2017).Empowerment of Female Governmental Preparatory School Teachers 'Knowledge and Practices Concerning First Aid \& Crisis Management at Al Jouf Region, Saudi Arabia . International Journal of Novel Research , 4 (1), 139-148.

[17]. Muneeswari, B. (2014). A study to assess the effectiveness of planned health teaching program using child-to-child approach on knowledge of selected first aid measures among school children in selected schools at Dharapuram in Tamil Nadu, India. Glob J Med Public Health, 3(1).

[18]. Olympia, R. P., Brady, J., Kapoor, S., Mahmood, Q., Way, E., \& Avner, J. R. (2010). Compliance of child care centers in Pennsylvania with national health and safety performance standards for emergency and disaster preparedness. Pediatric emergency care, 26(4), 239-247.
[19]. Potts, N. L., \& Mandleco, B. L.(2012). Pediatric nursing: Caring for children and their families. 3rded ., Canada : Delmar Cengage Learning .Chapter 1, P. 14.

[20]. Riad, N. A., Rabea, F. M., \&Badawy, A. I. (2013) - Capacity Building of Females Governmental Secondary School Teachers in Abha City For Crises Management \& First Aid. Journal of Education and Practice, 4(23), 33-41.

[21]. Singletary, E. M., Charlton, N. P., Epstein, J. L., Ferguson, J. D., Jensen, J. L., MacPherson, A. I., Zideman, D. A. 2015. Part 15: First aid: 2015 American Heart Association and American red cross guidelines update for first aid. Circulation, 132(18), 574-589..

[22]. Sönmez, Y., Uskun, E.,\& Pehlivan, A. 2014. Knowledge levels of pre-school teachers related with basic first-aid practices, Isparta sample. Turkish Pediatric Association, 49(3), 238-246.

[23]. Sugun , T. C. (2015).Women's Awareness about domestic accidents among toddlers .IJDR, 5(3), $3729-3733$.

[24]. Thomas, L., and Therese ,M .,(2015).study to assess the effectiveness of self-instructional module on knowledge regarding selected first aid measures among primary school teachers in Ernakulam district. International Journal of Medicine and Health Profession Research: 2(1), 17 - 31.

[25]. WHO, (2015) . Global health estimate . Deaths by cause, age, sex, by country and by region, 2015 . Geneva: World, Health Organization; 2016 (http://www.who.int/healthinfo/global_burden_dise ase/estimates/en/index1.html, accessed 22 March 2017 .

[26]. World health organization,(WHO).(2015) Children's environmental health: Injuries; 2015. Available at: http:// www.who.int/ceh/risks/cehinjuries/en/. Accessed November 9, 2015

[27]. World health organization, (WHO)( 2013). World Bank list of economies (July 2012). Washington, DC, World Bank; 2013 http://siteresources.worldbank. org/DATASTATISTICS/Resources/CLASS.XLS.

[28]. World health organization, (WHO) (2014). World Bank analytical income of economies for fiscal year; 2014 (July 2013). Washington, DC:

[29]. Younis, J. R., \& El-Abassy, A. (2015).Primary teachers' first aid management of children's school day accidents: Video-assisted teaching method versus lecture method. Journal of Nursing Education and Practice, 5(10), 60 